•论坛・

\title{
国家濒危物种红色名录的生物多样性保护意义
}

\author{
1 (中国科学院动物研究所, 北京 100101) \\ 2 (中国科学院大学, 北京 100049) \\ 3 (中国科学院成都生物研究所, 成都 610041) \\ 4 (中国科学院水生生物研究所, 武汉 430072) \\ 5 (北京师范大学生命科学学院, 北京 100875)
}

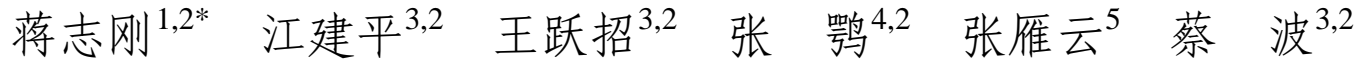

摘要: IUCN濒危物种红色名录与国家濒危物种红色名录都是物种灭绝风险的测度, 前者是全球性评估, 后者则是 国别研究。IUCN濒危物种红色名录预警了全球物种的濒危状况, 为全球生物多样性研究提供了大数据; 国别红色 名录确定了各国物种受威胁状况, 填补了前者的知识空缺, 两份名录互为补充。目前对国家濒危物种红色名录重 视不够。基于如下原因, 应当重视国别濒危物种红色名录的意义: (1)国家是濒危物种保护的行为主体, 物种在一个 国家的生存状况是确定其保护级别、开展濒危物种保育的依据; (2)对于仅分布于一个国家的特有物种来说, 其国 别濒危物种红色名录等级即是其全球濒危等级; (3)对于跨国境分布的物种来说, 国别濒危物种红色名录等级则确 定了该物种在本国的生存状况; (4)结合IUCN濒危物种红色名录, 国别濒危物种红色名录为建立跨国保护地、保护 迁徙物种的栖息地与跨国迁徙洄游通道提供依据; (5)国别濒危物种红色名录所特有的“区域灭绝”等级, 反映了一 个物种边缘种群在该国的区域灭绝, 恢复“区域灭绝”物种是该物种原分布国重引入保育工作的重点; (6)国别濒危 物种红色名录提供了该国物种编目、分类、分布和生存状况的最新信息。然而, 国别濒危物种红色名录的重要性 在许多情况下被忽视了。目前正值全球新冠肺炎大流行, 人们正在重新审视人与野生动物的关系。我国将修订有 关野生动物保护与防疫法法律以及《国家重点保护野生动物名录》, 防控新的人与野生动物共患疾病再次暴发。 对于确定国家重点保护野生动物物种名录来言, 物种受威胁程度是物种列为国家重点保护物种的特征之一。重视 国别红色名录有特别的意义。

关键词: 世界自然保护联盟濒危物种红色名录; 国家/区域濒危物种红色名录; 国家重点保护野生动物名录

\section{Significance of country red lists of endangered species for biodiversity conservation}

\author{
Zhigang Jiang ${ }^{1,2^{*}}$, Jianping Jiang ${ }^{3,2}$, Yuezhao Wang ${ }^{3,2}$, E Zhang ${ }^{4,2}$, Yanyun Zhang ${ }^{5}$, Bo Cai ${ }^{3,2}$ \\ 1 Institute of Zoology, Chinese Academy of Sciences, Beijing 100101 \\ 2 University of Chinese Academy of Sciences, Beijing 100049 \\ 3 Chengdu Institute of Biology, Chinese Academy of Sciences, Chengdu 610041 \\ 4 Institute of Hydrobiology, Chinese Academy of Sciences, Wuhan 430072 \\ 5 College of Life Sciences, Beijing Normal University, Beijing 100875
}

\begin{abstract}
Both the IUCN Red List of Endangered Species and country red lists of endangered species assess the risk of extinction of species, the former being a global assessment whereas the latter provides regional assessments. The IUCN Red List of Endangered Species alerts the world to the status of endangered species, and also serves as a database of global biodiversity. Country red lists, on the other hand, ascertain the status of species in particular countries, filling knowledge gaps in the former. The two lists are thus complementary to each other. However, insufficient attention has been paid to date to country red lists of endangered species. Country-level red lists should be given greater attention for at least the following reasons: (1) a sovereign
\end{abstract}

收稿日期: 2020-04-13; 接受日期: 2020-05-20

基金项目: 国家重点研发计划(2016YFC0503303)、中国科学院战略性先导科技专项子课题(XDA19050204; XDA23080101)和国家科技基础性专项 (2013FY110300)

* 通讯作者 Author for correspondence. E-mail: jiangzg@ioz.ac.cn 
country is the main authority for taking conservation action in regard to wildlife species within its boundaries based on the level of endangerment (conservation status) of the species; (2) for endemic species in a country, the country red list status constitutes its global status; (3) for species whose ranges cross national borders, the country's red list status reflects the survival status of the species in the country; (4) combined with the IUCN global red list, the country red list provides a basis from which to consider the establishment of transnational protected areas, the protection of important habitats for migratory species, and the protection of international migration corridors; (5) the category of "Regional Extinction" is unique to country/regional red lists of endangered species, providing an indication of the danger of extinction of the species at the country level; and (6) country red lists of endangered species can provide updated information on the inventory, classification, distribution and status of species in the country. Yet, the importance of country red lists is often overlooked under many different circumstances. Following onset of the global COVID-19 pandemic, however, people's outlook in China has been changing in regard to the relationship between humans and wildlife. Consequently, China will be amending national laws on wildlife protection, epidemic prevention, and the List of State Key Protected Wild Animal Species, in order to better prevent and control emerging zoonoses. The status of wildlife species included in the country red list of endangered species should be one of the defining elements for identifying and updating species on the List of State Key Protected Wild Animal Species in China. Thus, it is critical to recognize the significance of the country red list of endangered species at this special moment in time.

Key words: IUCN Red List of Endangered Species; country/regional red lists of endangered species; List of State Key Protected Wild Animal Species

生物多样性保护是时代主旋律。中国积极参与 了全球生物多样性行动, 保护了许多旗舰物种, 中 国生物多样性研究与保护在全球生物多样性研究 与保护中已经占据了重要位置(Mallapaty, 2020)。

濒危物种红色名录是物种灭绝风险的测度。

IUCN (International Union for Conservation of Nature) 自诞生之日起, 即开始制定濒危物种名单, 后来发 展为濒危物种红皮书、濒危物种红色名录(蒋志刚和 马克平, 2014; Lacher \& Hilton-Taylor, 2018)。目前, IUCN濒危物种红色名录汇集了各国的研究成果, 评估了 116,000 个物种, 发现超过31,000个种的生存 受到威胁, 受威胁种数(包括IUCN濒危物种红色名 录评估中的极危、濒危、易危三类物种) 占已评估物 种总数的 $27 \%$ (www.redlist.org)。其中 $41 \%$ 的两栖 类、34\%的针叶树种、33\%的珊瑚、30\%的鲨鱼、 $25 \%$ 的哺乳类以及 $14 \%$ 的鸟类的生存受到威胁。尽 管目前IUCN濒危物种红色名录尚未达到2020年评 估全球160,000个物种的目标, 但是IUCN濒危物种 红色名录是全球生物多样性的受胁等级编目, 影响 深远, 预警了全球物种的濒危状况, 被广泛用于全 球濒危物种研究(Rodrigues et al, 2006; Brooks et al, 2019; Cooke et al, 2019)。

世界各国均开展了国别濒危物种红色名录研 究, 为区域的濒危物种保护积累了重要资料
(Rodríguez, 2008)。近年来, 中国研究者也开展了大 型真菌(姚一建等, 2020; 魏铁铮等, 2020)、地衣(魏 金丽等, 2020)、石松类和蕨类(董仕勇等, 2017)、高 等植物(覃海宁等, 2017)、内陆鱼类(曹亮等, 2016)、 两栖类(江建平等, 2016)、爬行类(蔡波等, 2016)、鸟 类(张雁云等, 2016)、哺乳类(蒋志刚等, 2016b)的国 别红色名录研究。然而, 由于种种原因, 人们对国 别红色名录重要性的认识不足, 常常忽略了其应 用。国内研究者与保护工作者在评价中国分布的物 种的生存状况时, 绝大多数都引用了 IUCN濒危物 种红色名录评估的受胁等级, 却很少引用中国的国 别红色名录, 如《中国生物多样性红色名录》。

为了保护生物多样性, 中国在1989年开始实施 《中华人民共和国野生动物保护法》(以下简称《野 生动物保护法》)。四分之一个世纪之后, 全国人民 代表大会常务委员会组织了《野生动物保护法》的 修订, 以期适应新世纪的国家生态保护战略和全球 环境保护形势。《国家重点保护野生动物名录》(以 下简称《国家重点保护名录》) 作为《野生动物保护 法》的配套法律文件, 在《野生动物保护法》制定 一年后颁布实施, 将中国野生动物濒危种、稀有种 和旗舰种纳入了重点保护。《国家重点保护名录》 颁布后, 保护了中国珍稀濒危物种。随着中国生物 多样性研究的深入、物种保护与社会经济的发展带 
来的变化, 迫切需要更新《国家重点保护名录》。原 林业部在1998年，原国家林业局在2000年、2006年、 2009年和2011年，国家林业和草原局在2019年初曾 专门组织了《国家重点保护名录》修订专家研讨会, 召集野生动物专家和有关省市区野生动物管理专 家就修订调整《国家重点保护名录》进行论证(蒋志 刚, 2019)。然而, 仅在2006年, 为了扭转当时野生㭩 类种群数量下降的局面, 国家主管部门将中国鹿类 从国家二级重点保护野生动物升级为一级外, 《国 家重点保护名录》自颁布至今, 其他物种的保护级 别由于种种原因未曾调整, 也未曾增补新发现的种 类。学术界和公众要求修订更新《国家重点保护名 录》的呼声很高(马克平, 2016; 刘金等, 2019, 平晓 鸽和曾岩, 2020)。目前, 国家主管部门正在修订《国 家重点保护名录》, 物种濒危状况是判定物种保护 级别的重要依据。国别濒危物种红色名录对于生物 多样性保护来说意义重大。

各国对其境内的生物多样性拥有主权和责任 (https://www.cbd.int/convention/)。国家是受威胁物 种保护的行为主体。因此, 国家主管部门依据物种 在国内的生存状况评定保护优先顺序, 制定保护名 录, 建立保护地, 保护种群, 保存或恢复栖息地, 必要时采取迁地保护措施。保护濒危物种是国家战 略与国家行为。物种在一个国家的生存状况是开展 保育行动的依据。一个物种的分布区可能跨越多个 国家, 如环北极分布种驼鹿(Alces alces); 也可能仅 分布在一个国家，如中国特有的两栖爬行类，大鲵 (Andrias davidianus)、扬子鳄(Alligator sinensis)等。 各国的国别濒危物种红色名录反映物种在该国的 生存状况, 例如, 驼鹿在北美洲、欧洲的种群大, 分 布广，被IUCN濒危物种红色名录评为“无危”(LC), 但在中国仅分布在阿尔山和大兴安岭, 被中国生物 多样性红色名录评为“极危”(CR)。驼鹿在中国的濒 危等级是中国制定保护对策、采取保护行为的重要 依据。

分布国能及时更新评估特有种的生存状况。虽 然IUCN的目标是扩大濒危物种红色名录评估的种 类, 以了解全球生物物种的生存状况。但由于缺乏 足够的人力资源, IUCN 常常无法完成每 10 年更新 评估一次列入濒危物种红色名录物种的预定目标。 事实上, IUCN濒危物种红色名录中 $17 \%$ 的物种评估 已经过时(Rondinini et al, 2018)。对于仅分布于一个
国家的特有物种来说，国别濒危物种红色名录评估 的濒危等级即是其全球濒危等级，分布国濒危物种 红色名录等级是确定该物种IUCN红色名录等级的 参考。例如大熊猫(Ailuropoda melanoleuca)濒危等 级的降级。2015年, 《中国生物多样性红色名录》评 估时依据大熊猫的种群与栖息地状况，将其濒危等 级从“濒危”降到“易危”，这一结果由原环境保护部 与中国科学院联合发布(https://cn.bing.com/search?q= www.mee.gov.cn/gkml/hbb/bgg/201505/t20150525.\& form=IPRV10)。2016年, 在美国夏威夷举行的世界 自然保护大会上, IUCN红色名录工作组也采用了这 一评估结果。

国别濒危物种红色名录等级确定了跨国境分 布物种在该国的生存状况。例如，河狸(Castor fiber) 在中国的分布区为其边缘分布区(www.redlist.org)。 仅 700 只河狸分布在新疆阿勒泰地区布尔根、大小 清河流域, 濒临灭绝(Chu \& Jiang, 2009; 刘冬志等, 2013), 笔者2018年在新疆河狸分布区野外考察发 现其种群数量与分布与以前的报道没有变化。国别 红色名录评估其濒危等级为“极危”(CR), 是中国啮 齿目惟一的濒危种。而根据IUCN红色名录的评估, 河狸在全球其它分布区的种群数量还在增长, 其生 存状况为“无危”(LC)。中国《国家重点保护名录》 将河狸列为国家一级重点保护野生动物。河狸的 IUCN红色名录“无危”级别并不影响中国将河狸列 为国家级重点保护野生动物。类似地, 两栖动物新 疆北鲵(Ranodon sibiricus)主要分布于中亚地区的 哈萨克斯坦，在我国新疆伊犁地区邻近温泉县的4 个县有分布，其栖息地持续受到严重破坏(近年来 其栖息地状况有所好转), 国别红色名录评估其濒 危等级为“极危”(CR), 而 IUCN 的全球评估等级为 “濒危”(EN); 爬行动物中, 四爪陆龟 (Testudo horsfieldii)广泛分布于中亚多国，在我国新疆边境 地区霍城等地有发现，其栖息地持续受到严重破坏 (近年来其栖息地状况有所好转), 国别红色名录评 估其濒危等级为 “极危”(CR), 而 IUCN 的全球评估 等级为“易危”(VU)。

“区域灭绝”种是一个国家重引入保护的重点。 国别濒危物种红色名录有 IUCN濒危物种红色名录 所没有的“区域灭绝”(RE)等级，用于反映一个物种 在一个国家(一个区域)分布种群的消失，警示了区 域的生物多样性危机。“区域灭绝”物种应是原分布 
国优先引入重建野生种群的重点对象。根据《中国 生物多样性红色名录. 脊椎动物》2020版的评估结果, 中国有 10 种有蹄类已经 “局部灭绝”或 “野外灭 绝”(EW), 占中国有蹄类(偶蹄目 + 奇蹄目)种类的 $1 / 7$ 。在Bar-On等(2018)列出的世界上体重最重的 10 种有蹄类动物中, 有 5 种已经在中国灭绝或极度濒 危。在中国局部灭绝的大型有蹄类, 如独角犀 (Rhinoceros unicornis) (蒋志刚等, 2016a)、爪哇野牛 (Bos javanicus), 需要重引入, 2018年长隆野生动物 世界与上海野生动物园各从尼泊尔重新引入了 1 对 独角犀。一些已经重引入的物种, 如高鼻羚羊(Saiga tairica)在20世纪80年代重引入甘肃武威, 经历遗传 瓶颈和疾病后, 目前种群比引入时的建群种群还小 (Jiang et al, 2020, preprint), 其濒危等级仍是“野外 灭绝”(EW)。同期引入的普氏野马(Equus ferus), 20 世纪中叶在中国灭绝, 目前已经在新疆卡拉麦里 山、安西极旱荒漠、敦煌西湖等自然保护区实施野 外放养, 但是尚未建立野生种群(Jiang \& Zong, 2019)。于是，尽管中国“区域灭绝”的野马已经重引 入, 但其中国生物多样性红色名录濒危等级仍是 “野外灭绝”(EW), 而由于其野生种群在蒙古的恢复 重建, IUCN红色名录将全球普氏野马的濒危等级 降为“濒危”(EN)。中国有尾类两栖动物中, 琉球棘 螈(Echinotriton andersoni) 曾于 20世纪30年代在我 国台湾省北部有标本记录, 但之后没有再发现(Zhao \& Adler, 1993); 故中国国别红色名录评估时将琉球 棘螈评估为“区域灭绝”(RE)。然而，目前该物种在 冲绳、阿美等岛屿仍较容易发现。

国别红色名录评估鉴别了跨境分布区与迁徙 通道。《迁徙物种公约》关注恢复跨越国境分布物 种的种群与栖息地以及跨国迁徙通道的保护(蒋志 刚等, 2019)。中国的社会、自然环境状况和野生动 物种群数量与栖息地的显著变化, 使得许多野生动 物在中国的分布区退缩到边境地区, 如东北虎 (Panthera tigris altaica) (Wang et al, 2016)、蒙古原 羚(Procapra gutturosa) (Luo et al, 2014)、亚洲象 (Elephas maximus) (Zhang et al, 2015)等。亚洲象、 东北虎、犀牛等的原分布区被人类活动区挤占, 加 之环境变迁, 其分布区逐渐从中国消失(Wan et al, 2019)。这种野生动物栖息地在人类世(Anthropocene) 被人类活动、环境变迁 “挤占擦除”的现象是其濒危 原因之一。结合IUCN红色名录, 国别濒危物种红色
名录可以建立跨国保护地、恢复这些动物的原有栖 息地，保护迁徙物种跨国迁徙洄游通道，为跨越国 境分布的野生动物保护提供依据。

国别濒危物种红色名录是物种编目与生存状 况的及时更新。相对研究区域而言，一个国别濒危 物种红色名录研究的投入比IUCN全球评估时对该 国评估投入的相对比例大。国别濒危物种红色名录 评估集中了一个国家的濒危物种研究与保护专家。 参与国别濒危物种红色名录评估的研究人员对本 国研究不存在语言障碍(Fisher, 2014), 掌握包括灰 色文献在内的该国物种编目、分类、分布和种群的 最新信息，能提供物种生存状况的最新资料(Jiang et al, 2016)。《中国生物多样性红色名录·脊椎动物》 2020版评估的两栖类种数从2015年的 408 种, 增加 到2020年的475种; 评估的爬行类种数从2015年的 462种, 增加到 2020 年的 527 种; 评估的鸟类种数从 2015年的1,372种，增加到2020年的 1,445 种; 评估 的哺乳类种数从 2015 年的673种，增加到2020年的 696种。2015年《中国脊椎动物红色名录》比2015 年IUCN红色名录多评估了 60 种哺乳类，爬行类则 多评估了 227种; 尽管IUCN红色名录研究团队与中 国生物多样性红色名录研究团队有交流，《中国生 物多样性红色名录. 脊椎动物》2020版仍比IUCN红 色名录多评估了54种哺乳类, 124种爬行类(图1)。这 些种是新种、新分布记录种或者被IUCN红色名录 工作组认为在中国没有分布的种，例如，IUCN红色 名录(2020版)仍将中国标示在驼鹿与河狸的分布区 之外(www.redlist.org)。因此，我们在制定国家重点 保护物种名录时，应重视国别濒危物种红色名录 的意义。

人们对国别濒危物种红色名录重视不够(曹亮 等, 2016)。国别濒危物种红色名录的重要性在许多 情况下被忽视了。在研究报告和科普作品中, 论及 物种濒危属性时, 作者通常言必IUCN濒危物种红 色名录濒危等级而不提其国家红色名录濒危等级。 殊不知, IUCN濒危物种红色名录预警了全球物种 的濒危状况, 为全球生物多样性研究提供了大数据, 而国别濒危物种红色名录确定了物种在该国的受 威胁状况，填补了全球濒危物种红色名录的知识空 白, 两份名录互为补充。受胁物种是国家重点保护 物种的特征之一(蒋志刚, 2019)。描述一个物种的受 胁程度时，国别濒危物种红色名录等级在实践意义 
A: 哺乳类 Mammals

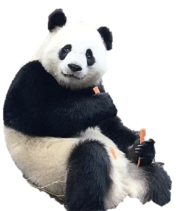

B: 鸟类 Birds

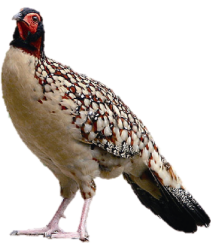

崩

C: 爬行类 Reptiles

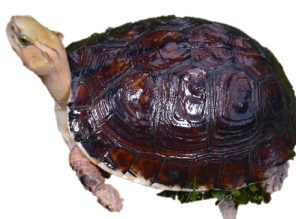

D: 两栖类 Amphibians

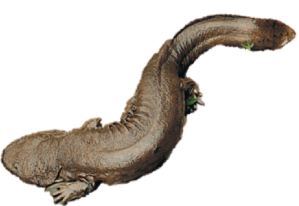

\begin{tabular}{|c|c|c|c|c|c|c|c|c|c|c|c|c|}
\hline & \multicolumn{12}{|c|}{ IUCN濒危物种红色名录2020版 IUCN Red List of Endangered Species 2020} \\
\hline \multirow{2}{*}{ 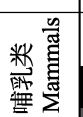 } & & 灭绳 EX & $\begin{array}{c}\text { 野外灭纸 } \\
\text { EW }\end{array}$ & $\begin{array}{l}\text { 区域灭 } \\
\text { RE }\end{array}$ & 极危 CR & 濒危 EN & 易危 VU & 近危 N & 无危 LC & $\begin{array}{l}\text { 数据缺乏 } \\
\text { DD }\end{array}$ & $\begin{array}{c}\text { 未评估 } \\
\mathrm{NE}\end{array}$ & 总计 Sum \\
\hline & 灭绝 $\mathrm{EX}$ & 0 & 0 & 0 & 0 & 0 & 0 & 0 & 0 & 0 & 0 & 0 \\
\hline \multirow{9}{*}{ 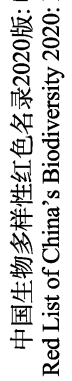 } & 野外灭绝 EW & 0 & 0 & 0 & 1 & 1 & 0 & 0 & 1 & 0 & 1 & 4 \\
\hline & 区域灭绝 $\mathrm{RE}$ & 0 & 0 & 0 & 2 & 3 & 1 & 0 & 0 & 0 & 0 & 6 \\
\hline & 极危 CR & 0 & 1 & 0 & 8 & 11 & 16 & 4 & 7 & 1 & 6 & 54 \\
\hline & 濒危 $\mathrm{EN}$ & 0 & 0 & 0 & 0 & 16 & 10 & 7 & 14 & 4 & 8 & 59 \\
\hline & 易伦 VU & 0 & 0 & 0 & 0 & 3 & 9 & 5 & 40 & 4 & 7 & 68 \\
\hline & 近危 NT & 0 & 0 & 0 & 0 & 0 & 0 & 14 & 114 & 13 & 7 & 148 \\
\hline & 无危 LC & 0 & 0 & 0 & 0 & 1 & 0 & 3 & 251 & 6 & 5 & 266 \\
\hline & 数据铁乏 DD & 0 & 0 & 0 & 0 & 1 & 2 & 1 & 39 & 28 & 20 & 91 \\
\hline & 总计 Sum & 0 & 1 & 0 & 11 & 36 & 38 & 34 & 466 & 56 & 54 & 696 \\
\hline
\end{tabular}

\begin{tabular}{|c|c|c|c|c|c|c|c|c|c|c|c|}
\hline & \multicolumn{11}{|c|}{ IUCN 濒危物种红色名录2020版 IUCN Red List of Endangered Species 2020} \\
\hline \multirow{11}{*}{ 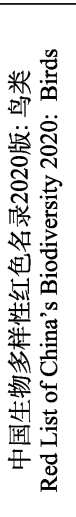 } & & 灭绝 EX & $\begin{array}{c}\text { 野外灭绝 } \\
\text { EW }\end{array}$ & 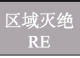 & 极危 CR & 濒危 $\mathrm{EN}$ & 易危 Vu & 近危 NT & 无危 LC & $\begin{array}{c}\text { 数据缺乏 } \\
\text { DD }\end{array}$ & 总计 Sum \\
\hline & 灭绝 $\mathrm{EX}$ & 0 & 0 & 0 & 0 & 0 & 0 & 0 & 0 & 0 & 0 \\
\hline & 野外灭绝 EW & 0 & 0 & 0 & 0 & 0 & 0 & 0 & 0 & 0 & 0 \\
\hline & 区域灭络 RE & 0 & 0 & 0 & 0 & 0 & 1 & 1 & 1 & 0 & 3 \\
\hline & 极危 $\mathrm{CR}$ & 0 & 0 & 0 & 8 & 4 & 3 & 1 & 2 & 0 & 18 \\
\hline & 渐危 $\mathrm{EN}$ & 0 & 0 & 0 & 0 & 15 & 20 & 3 & 10 & 0 & 48 \\
\hline & 易危 VU & 0 & 0 & 0 & 0 & 4 & 25 & 16 & 34 & 0 & 79 \\
\hline & 近危 NT & 0 & 0 & 0 & 0 & 1 & 8 & 41 & 172 & 0 & 222 \\
\hline & 无危 LC & 0 & 0 & 0 & 0 & 1 & 4 & 16 & 948 & 0 & 969 \\
\hline & 数据缺乏 DD & 0 & 0 & 0 & 6 & 3 & 16 & 14 & 65 & 2 & 106 \\
\hline & 总计 Sum & 0 & 0 & 0 & 14 & 28 & 77 & 92 & 1,232 & 2 & 1,445 \\
\hline
\end{tabular}

\begin{tabular}{|c|c|c|c|c|c|c|c|c|c|c|c|c|}
\hline & \multicolumn{12}{|c|}{ IUCN 濒危物种红色名录2020版 IUCN Red List of Endangered Species 2020} \\
\hline \multirow{12}{*}{ 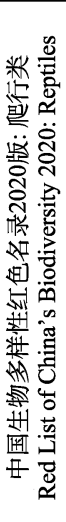 } & & 灭绝 EX & $\begin{array}{c}\text { 野外灭绝 } \\
\text { EW }\end{array}$ & $\begin{array}{c}\text { 区域灭绝 } \\
\end{array}$ & 极危 CR & 濒危 EN & 易危 VU & 近危 NT & 无危 LC & $\begin{array}{l}\text { 数据缺乏 } \\
\text { DD }\end{array}$ & $\begin{array}{c}\text { 未评估 } \\
\mathrm{NE}\end{array}$ & 总计 Sum \\
\hline & 灭绝 EX & 0 & 0 & 0 & 0 & 0 & 0 & 0 & 0 & 0 & 0 & 0 \\
\hline & 野外灭绝 EW & 0 & 0 & 0 & 0 & 0 & 0 & 0 & 0 & 0 & 0 & 0 \\
\hline & 区㳦灭绝 RE & 0 & 0 & 0 & 0 & 0 & 1 & 0 & 1 & 0 & 0 & 2 \\
\hline & 极危 CR & 0 & 0 & 0 & 15 & 9 & 5 & 2 & 3 & 0 & 1 & 35 \\
\hline & 濒危 EN & 0 & 0 & 0 & 0 & 13 & 6 & 0 & 12 & 1 & 11 & 43 \\
\hline & 易危 VU & 0 & 0 & 0 & 0 & 0 & 7 & 0 & 26 & 2 & 35 & 70 \\
\hline & 近危 NT & 0 & 0 & 0 & 0 & 1 & 1 & 7 & 31 & 3 & 22 & 65 \\
\hline & 无危 LC & 0 & 0 & 0 & 0 & 0 & 0 & 0 & 142 & 4 & 41 & 187 \\
\hline & 数据缺乏 DD & 0 & 0 & 0 & 0 & 0 & 0 & 0 & 16 & 21 & 40 & 77 \\
\hline & 未评估 NE & 0 & 0 & 0 & 0 & 0 & 0 & 0 & 0 & 0 & 48 & 48 \\
\hline & 总计 Sum & 0 & 0 & 0 & 15 & 23 & 20 & 9 & 231 & 31 & 198 & 527 \\
\hline
\end{tabular}

\begin{tabular}{|c|c|c|c|c|c|c|c|c|c|c|c|c|}
\hline & \multicolumn{12}{|c|}{ IUCN 濒危物种红色名录2020版 IUCN Red List of Endangered Species 2020} \\
\hline \multirow{12}{*}{ 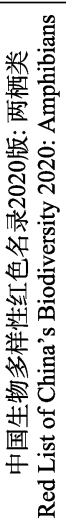 } & & 灭绝 EX & $\begin{array}{c}\text { 野外灭绝 } \\
\mathrm{EW}\end{array}$ & $\begin{array}{l}\text { 区域灭绝 } \\
\text { RE }\end{array}$ & 极危 CR & 擞危 $\mathrm{EN}$ & 易危 VU & 近危 NT & 无危 LC & $\begin{array}{c}\text { 数据缺乏 } \\
\text { DD }\end{array}$ & $\begin{array}{c}\text { 未评估 } \\
\mathrm{NE}\end{array}$ & 总计 Sum \\
\hline & 灭绳 $\mathrm{EX}$ & 1 & 0 & 0 & 0 & 0 & 0 & 0 & 0 & 0 & 0 & 1 \\
\hline & 野外灭绝 EW & 0 & 0 & 0 & 0 & 1 & 0 & 0 & 0 & 0 & 0 & 1 \\
\hline & 区域灭绝 RE & 0 & 0 & 0 & 0 & 0 & 0 & 0 & 0 & 0 & 0 & 0 \\
\hline & 极危 CR & 0 & 0 & 0 & 5 & 2 & 0 & 0 & 0 & 3 & 2 & 12 \\
\hline & 濒危 EN & 0 & 0 & 0 & 1 & 19 & 4 & 1 & 1 & 7 & 14 & 47 \\
\hline & 易危 VU & 0 & 0 & 0 & 1 & 14 & 31 & 7 & 28 & 14 & 22 & 117 \\
\hline & 近危 NT & 0 & 0 & 0 & 0 & 1 & 8 & 23 & 36 & 11 & 18 & 97 \\
\hline & 无危 LC & 0 & 0 & 0 & 0 & 1 & 4 & 2 & 89 & 10 & 12 & 118 \\
\hline & 数据缺乏 $\mathrm{DD}$ & 0 & 0 & 0 & 0 & 2 & 8 & 2 & 5 & 31 & 33 & 81 \\
\hline & 未评估 $\mathrm{NE}$ & 0 & 0 & 0 & 0 & 0 & 0 & 0 & 0 & 0 & 1 & 1 \\
\hline & 总计 Sum & 1 & 0 & 0 & 7 & 40 & 55 & 35 & 159 & 76 & 102 & 475 \\
\hline
\end{tabular}


上更重要、更符合物种的实际生存状况。目前正值 全球新冠肺炎大流行, 中国取得了防控新冠肺炎的 初步成果。为了防控新的人与野生动物共患疾病再 次暴发, 人们正在重新审视人与野生动物的关系 (Andersen et al, 2020; 蒋志刚, 2020)。我国将修订有 关野生动物保护与防疫法法律以及《国家重点保护 野生动物名录》。有必要重新认识国别物种红色名录 的重要作用。今后国家重点保护名录更新和制定中, 当中国红色名录与IUCN红色名录的评估结果不一 致的时候，应当首先考虑中国红色名录的濒危等级。

\section{参考文献}

Andersen KG, Rambaut A, Lipkin WI, Holmes EC, Garry RF (2020) The proximal origin of SARS-CoV-2. Nature Medicine, 26, 450-452.

Bar-On YM, Phillips R, Milo R (2018) The biomass distribution on Earth. Proceedings of the National Academy of Sciences, USA, 115, 6506-6511.

Brooks TM, Pimm SL, Akçakaya HR, Buchanan GM, Butchart SHM, Foden W, Hilton-Taylor C, Hoffmann M, Jenkins CN, Joppa L, Li BV, Menon V, Ocampo-Peñuela N, Rondinini C (2019) Measuring terrestrial area of habitat $(\mathrm{AOH})$ and its utility for the IUCN Red List. Trends in Ecology and Evolution, 34, 977-984.

Cai B, Li JT, Chen YY, Wang YZ (2016) Exploring the status and causes of China's threatened reptiles through the red list assessment. Biodiversity Science, 24, 578-587. (in Chinese with English abstract) [蔡波, 李家堂, 陈跃英, 王跃招 (2016) 通过红色名录评估探讨中国爬行动物受威胁现状 及原因. 生物多样性, 24, 578-587.]

Cao L, Zhang E, Zang CX, Cao WX (2016) Evaluating the status of China's continental fish and analyzing their causes of endangerment through the red list assessment. Biodiversity Science, 24, 598-609. (in Chinese with English abstract) [曹 亮, 张鹗, 藏春共, 曹文宣 (2016) 通过红色名录评估研 究中国内陆鱼类受威胁现状及其成因. 生物多样性, 24, 598-609.]

Chu HJ, Jiang ZG (2009) Distribution and conservation of Sino-Mongolian beaver, Castor fiber. Oryx, 43, 197-202.

Cooke RSC, Eigenbrod F, Bates AE (2019) Projected losses of global mammal and bird ecological strategies. Nature Communications, 10, 2279.

Dong SY, Zuo ZY, Yan YH, Xiang JY (2017) Red list assessment of lycophytes and ferns in China. Biodiversity Science, 25, 765-773. (in Chinese with English abstract) [董 仕勇, 左政裕, 严岳鸿, 向建英 (2017) 中国石松类和蒴 类植物的红色名录评估. 生物多样性, 25, 765-773.]

Fisher M (2014) A literature for all conservationists, everywhere? Oryx, 23, 1-2.

Jiang JP, Xie F, Zang CX, Cai L, Li C, Wang B, Li JT, Wang J, Hu JH, Wang Y, Liu JY (2016) Assessing the threat status of amphibians in China. Biodiversity Science, 24, 588-597. (in Chinese with English abstract) [江建平, 谢锋, 藏春金金, 蔡蕾, 李成, 王斌, 李家堂, 王杰, 胡军华, 王燕, 刘畑宇 （2016）中国两栖动物受威胁现状评估. 生物多样性, 24, 588-597.]

Jiang ZG, Ma KP (2014) Principles of Conservation Biology. Science Press, Beijing. (in Chinese) [蒋志刚, 马克平 (2014) 保护生物学原理. 科学出版社, 北京.]

Jiang ZG, Cui SP, Li CW (2016a) Where are the suitable introduction sites of greater one-horned rhinoceros Rhinoceros unicornis in China? Biodiversity Science, 24, 355-357. (in Chinese) [蒋志刚, 崔绍朋, 李春旺 (2016a) 中国引入大独角犀的适宜地点在哪里? 生物多样性, 24, 355-357.]

Jiang ZG, Li LL, Luo ZH, Tang SH, Li CW, Hu HJ, Ma Y, Wu Y, Wang YX, Zhou KY, Liu SY, Feng ZJ, Cai L, Zang CX, Zeng Y, Meng ZB, Ping XG, Fang HX (2016b) Evaluating the status of China's mammals and analyzing their causes of endangerment through the red list assessment. Biodiversity Science, 24, 552-567. (in Chinese with English abstract) [蒋 志刚, 李立立, 罗振华, 汤宋华, 李春旺, 胡慧建, 马勇, 吴毅, 王应祥, 周开亚, 刘少英, 冯祚建, 蔡蕾, 藏春釒錪, 曾岩, 孟智斌, 平晓鸽, 方红霞 (2016b) 通过红色名录 评估研究中国哺乳动物受威胁现状及其原因. 生物多样 性, 24, 552-567.]

Jiang Z, Jiang J, Wang Y, Zhang E, Zhang Y, Li L, Cai B, Luo Z, Li C, Ping X, Xie F, Cao L (2016) China's ecosystems: Overlooked species. Science, 353, 657.

Jiang ZG (2019) China's key protected species lists, their criteria and management. Biodiversity Science, 27, 698-703. (in Chinese with English abstract) [蒋志刚 (2019) 中国重 点保护物种名录、标准与管理. 生物多样性, 27, 698-703.]

图 1 中国生物多样性红色名录哺乳类 $(A)$ 、鸟类 $(B)$ 、爬行类 $(C)$ 和两栖类 $(D)$ 与 IUCN 红色名录评估的相应类群的评估种类 与濒危等级的差异。插图依次为大熊猫(Ailuropoda melanoleuca)、黄腹角雉(Tragopan caboti)、百色闭壳龟(Cuora mccordi)、 大鲵(Andrias davidianus); 摄影者分别为蒋志刚、张雁云、蔡波、江建平。

Fig. 1 Differences between species assessed and endangerment categories between the Red List of China's Biodiversity: Mammals (A), Birds (B), Reptiles (C) and Amphibians (D) in the corresponding fauna in IUCN Red List of Endangered Species. Photos are giant panda (Ailuropoda melanoleuca), Cabot's tragopan (Tragopan caboti), Mccord's box turtle (Cuora mccordi), giant salamander (Andrias davidianus), taken by Zhigang Jiang, Yanyun Zhang, Bo Cai, Jianping Jiang, respectively. NE, Not Evaluated; DD, Data Deficient; LC, Least Concern; NT, Near Threatened; VU, Vulnerable; EN, Endangered; CR, Critically Endangered; RE, Regional Extinct; EW, Extinct in the Wild; EX, Extinct. 
Jiang ZG, Zhang ZW, Zhang RZ, Ma ZJ, Chu HJ, Li YM, Ding CQ, Zhao YH, Xu JL, Ping XG, Zeng Y, Cui SP, Li N, Cao DD, Wang SP, Xu J, Qi YJ, Li CW (2019) Ratifying Bonn Convention, promoting global conservation of migratory animals. Biodiversity Science, 27, 1393-1395. (in Chinese) [蒋志刚, 张正旺, 张润志, 马志军, 初红军, 李义明, 丁 长青, 赵亚辉, 徐基良, 平晓鸽, 曾岩, 崔绍朋, 李娜, 曹 丹丹, 王苏盆, 徐婧, 戚英杰, 李春旺 (2019) 加入《迁徙 物种公约》, 促进全球迁徙动物保护. 生物多样性, 27, 1393-1395.]

Jiang ZG, Zong H (2019) Reintroduction of the Przewalsi's horse in China: Status quo and outlook. Nature Conservation Research, (4) (Suppl. 2), 15-22.

Jiang ZG (2020) Insights on the legislation, law enforcement and management of zoonosis from the epidemic of new coronavirus pneumonia (COVID-19). Biodiversity Science, 28, 256-261. (in Chinese with English abstract) [蒋志刚 (2020) 新型冠状病毒肺炎对野生动物疫病立法执法与管 理的启迪. 生物多样性, 28, 256-261.]

Jiang ZG, Mallon D, Foggin M, Li CW, Cui SP, Zeng Y, Ping XG (2020) A case of reintroducing Saiga highlights the conservation needs of migratory species. doi:10.20944/ preprints202002.0375.v1Preprints.

Lacher TE, Hilton-Taylor C (2018) The IUCN Red List: Assessing extinction risk in the Anthropocene. Encyclopedia of the Anthropocene, 3, 333-339.

Liu DZ, Jiang ZG, Chu HJ, Huang XW, Zhang F, Chen G (2013) Summer nocturnal activity rhythms and time budgets of the Sino-Mongolia beaver (Castor fiber birulai) in Xinjiang, China. Acta Theriologica Sinica, 33, 319-325. (in Chinese with English abstract) [刘冬志, 蒋志刚, 初红军, 黄效文, 张帆, 陈刚 (2013) 蒙新河狸夏季夜间活动节律 和时间分配. 兽类学报, 33, 319-325.]

Liu J, Que PJ, Zhang ZW (2019) Species diversity and suggestions for adjustment of the national protection level of waterbirds in China. Wetland Science, 17, 123-136. (in Chinese with English abstract) [刘金, 阙品甲, 张正旺 (2019) 中国水鸟的物种多样性及其国家重点保护等级调 整的建议. 湿地科学, 17, 123-136.]

Luo Z, Liu B, Liu S, Jiang Z, Halbrook RS (2014) Influences of human and livestock density on winter habitat selection of Mongolian gazelle (Procapra gutturosa). Zoological Science, 31, 20-30.

Ma KP (2016) On key issues and possible solutions related to nature reserve management in China. Biodiversity Science, 24, 249-251. (in Chinese) [马克平 (2016) 当前我国自然 保护区管理中存在的问题与对策思考. 生物多样性, 24, 249-251.]

Mallapaty S (2020) China takes centre stage in global biodiversity push. Nature, 578, 345-346.

Ping XG, Zeng Y (2020) Changes in nomenclature of animals included in Lists of Wild Animals under Special State Protection in China and impacts on wildlife conservation.
Scientia Sinica Vitae, 50, 33-43. (in Chinese with English abstract) [平晓鸽, 曾岩 (2020) 《国家重点保护野生动物 名录》所列物种命名变化及其对野生生物保护的影响. 中 国科学: 生命科学, 50, 33-43.]

Qin HN, Yang Y, Dong SY, He Q, Jia Y, Zhao LN, Yu SX, Liu HY, Liu B, Yan YH, Xiang JY, Xia NH, Peng H, Li ZY, Zhang ZX, He XJ, Yin LK, Lin YL, Liu QR, Hou YT, Liu Y, Liu QX, Cao W, Li JQ, Chen SL, Jin XH, Gao TG, Chen WL, Ma HY, Geng YY, Jin XF, Chang CY, Jiang H, Cai L, Zang CX, Wu JY, Ye JF, Lai YJ, Liu B, Lin QW, Xue NX (2017) Threatened Species List of China's Higher Plants. Biodiversity Science, 25, 696-744. (in Chinese and in English) [覃海宁, 杨永, 董仕勇, 何强, 贾渝, 赵莉娜, 于胜祥, 刘慧圆, 刘博, 严岳鸿, 向建英, 夏念和, 彭华, 李振宇, 张志翔, 何兴金, 尹林克, 林余霖, 刘全儒, 侯 元同，刘演，刘启新，曹伟，李建强，陈世龙，金效华，高 天刚, 陈文俐, 马海英, 耿玉英, 金孝锋, 常朝阳, 蒋宏, 蔡蕾, 蔵春金金, 武建勇, 叶建飞, 赖阳均, 刘冰, 林秦文, 薛纳新 (2017) 中国高等植物受威胁物种名录. 生物多 样性, 25, 696-744.]

Rodrigues SLA, Pilgrim JD, Lamoreux JF, Hoffmann M, Brooks TM (2006) The value of the IUCN Red List for conservation. Trends in Ecology and Evolution, 21, 71-76.

Rodríguez JP (2008) National red lists: The largest global market for IUCN Red List Categories and Criteria. Endangered Species Research, 6, 193-198.

Rondinini C, Di Marco M, Visconti P, Butchart HMS, Boitani L (2018) Update or outdate: Long-term viability of the IUCN Red List. Conservation Letters, 7, 126-130.

Wan X, Jiang G, Yan C, He F, Wen R, Gu J, Li X, Ma J, Stenseth NC, Zhang Z (2019) Historical records reveal the distinctive associations of human disturbance and extreme climate change with local extinction of mammals. Proceedings of the National Academy of Sciences, USA, 116, 19001-19008.

Wang TM, Feng LM, Mou P, Wu JG, Smith JLD, Xiao WH, Yang HT, Dou HL, Zhao XD, Cheng YC, Zhou B, Wu HY, Zhang L, Tian Y, Guo QX, Kou XJ, Han XM, Miquelle DG, Oliver CD, Xu RM, Ge JP (2016) Amur tigers and leopards returning to China: Direct evidence and a landscape conservation plan. Landscape Ecology, 31, 491-503.

Wei TZ, Wang K, Yu XD, Li Y, Wu HJ, Wu HM, Wang YH, Wei XD, Li BB, Jiang L, Yao YJ (2020) Assessment of the threatened status of macro-basidiomycetes in China. Biodiversity Science, 28, 41-53. (in Chinese with English abstract) [魏铁铮, 王科, 于晓丹, 李熠, 吴海军, 吴红梅, 王永会, 卫晓丹, 李斌斌, 蒋岗, 姚一建 (2020) 中国大 型担子菌受威胁现状评估. 生物多样性, 28, 41-53.]

Wei XL, Deng H, Wei JC (2020) Threatened categories assessment of lichens in China. Biodiversity Science, 28, 54-65. (in Chinese with English abstract) [魏金丽丽, 邓红, 魏江春 (2020) 中国地衣的濒危等级评估. 生物多样性, 28, 54-65.] 
Yao YJ, Wei JC, Zhuang WY, Wei TZ, Li Y, Wei XL, Deng H, Liu DM, Cai L, Li JS, Wang K, Wu HJ, Li BB, Wang YH, Wei XD, Wu HM, Zhao MJ, Yang L, Su JH, Zhong X (2020) Threatened species list of China's macrofungi. Biodiversity Science, 28, 20-25. (in Chinese and in English) [姚一建, 魏江春, 庄文颖, 魏铁铮, 李熠, 魏金丽, 邓红, 刘冬梅, 蔡蕾, 李俊生, 王科, 吴海军, 李斌斌, 王永会, 卫晓丹, 吴红梅, 赵明君, 杨柳, 苏锦河, 钟习 (2020) 中国大型真菌受威胁物种名录. 生物多样性, 28, 20-25.]

Zhang L, Dong L, Lin L, Feng L, Yan F, Wang L, Guo X, Luo A (2015) Asian elephants in China: Estimating population size and evaluating habitat suitability. PLoS ONE, 10, e0124834.

Zhang YY, Zhang ZW, Dong L, Ding P, Ding CQ, Ma ZJ, Zheng GM (2016) Assessment of red list of birds in China. Biodiversity Science, 24, 568-577. (in Chinese with English abstract) [张雁云, 张正旺, 董路, 丁平, 丁长青, 马志军, 郑光美 (2016) 中国鸟类红色名录评估. 生物多样性, 24, 568-577.]

Zhao EM, Adler K (1993) Herpetology of China. Society for the Study of Amphibians and Reptiles, Oxford, Ohio.

(责任编委: 吕植 责任编辑: 问文杰) 